\title{
Effect of Environmental-Economic Imbalances at Sustainable Development of the Russian Federation
}

\author{
Nurtdinov R. M. ${ }^{1} \&$ Nurtdinov A. R. ${ }^{1}$ \\ ${ }^{1}$ Kazan Federal University, Institute of Management, Economics and Finance, Kazan, Russia \\ Correspondence: Nurtdinov A. R., Kazan Federal University, Institute of Management, Economics and Finance, \\ Kazan, 420008, Russia. Tel: 7-900-321-8408. E-mail: nurtdinov1985@gmail.com
}

Received: December 27, 2014

Accepted: February 19, 2015 Online Published: April 30, 2015

doi:10.5539/ass.v11n11p84

URL: http://dx.doi.org/10.5539/ass.v11n11p84

\begin{abstract}
The article ecological-economic system is viewed through the prism of the equilibrium and non-equilibrium situation, we study the main factors determining the position of the non-equilibrium of the world economy and the national economy, the results of Russia's economic growth is adjusted with the use of the index of net savings. In addition, the article proves that one of the reasons for the negative phenomena in ecological-economic sphere is the imperfection used macroeconomic indicators such as GDP and GNP.
\end{abstract}

Keywords: ecological-economic system, environmental-economic imbalances, ecological and economic crisis, factors of disequilibrium, natural environment, genuine savings, nature of economic growth

\section{Introduction}

Socio-economic development of the Russian Federation in the last decade was characterized by a number of positive changes: in a short time managed to recover from the consequences of default, to move from recession to growth of production, improve the living standards of the population, as well as begin to address a number of pressing social problems. At the same time, economic growth was largely due to external economic conditions, high world prices for hydrocarbons, influx of foreign loans at relatively low interest rates. Markedly exacerbated problems in the interaction between society and the natural environment. The threat of serious environmental disasters has become one of the key problems of socio-economic development. Unity of economic, social and environmental issues necessitates radical modernization and sustained, deep institutional reforms of the economic system of the country, aimed at creating a diversified, competitive and socially-oriented post-industrial economy, capable of sustainable economic and social development.

\section{Method}

In the process of writing articles used scientific methods of knowledge: scientific abstraction, induction and deduction, historical and logical methods, analysis and synthesis, as well as the methods of the system, the structural-functional and economic and statistical analysis.

\section{Results}

The ecological-economic system, which is made of a complex and contradictory set of elements, connections, and relationships, is in dynamic interaction, alternately taking an equilibrium and non-equilibrium state. Under the ecological and economic equilibrium we understand the position of strength and stability inherent in the system of relationships, a balance between economic, social, and environmental spheres. There is a certain optimum balance between economic potential and quality of life of the society, compliance with environmental practices, and rational criteria for the development and rehabilitation of the environment with adequate support of production of natural resources. The ecological-economic system is influenced by different factors in the external and internal environment, so the equilibrium state is relative, temporary, and transitory. The main factor that disturbs the equilibrium is human intervention in the natural environment and their production activities. Resist the tendency to this influence; it tends to return the ecological-economic system to the equilibrium state in the new and changed conditions. This - the factors that ensure the optimum position of the environmental protection regime of human activity. The equilibrium state seems ideal and so difficult to attain; more frequent is the non-equilibrium position. As a result, quantitative accumulation of negative ecological and economic changes leads to a transition to a qualitatively new state, defined as non-equilibrium. If the measure of human 
intervention in the environment passes a critical threshold and contradictions reach their extreme severity, instability develops into a crisis. Consider the main reasons related to environmental and economic disequilibrium; among them - population growth, increased consumption of natural resources, and increased production. The world population has passed at the beginning of the XXI century 7 billion and continues to grow (Huning, Naumann, Bens, \& Hüttl, 2011).

However, the distribution of the population and changes in its population differ by region. The most difficult situation is in developing countries, where growth is larger than in developed countries, where, in the second half of the twentieth century, growth stopped, and then began to decline. Population growth, on the one hand, aggravates social problems, and on the other is pushing to further enhance economic growth with increasing environmental burden. According to experts, population growth of $1 \%$ must comply with GDP growth of $2 \%$ in order to maintain the current standard of living. Development of the world economy, despite the achievements of scientific and technological progress, is accompanied by an ever-increasing consumption of natural resources.

More than 185 billion tons of coal and 45-50 billion tons of iron ore were extracted over the last hundred years, with 1960-2000 accounting for more than half (Safiullin, Ismagilova, Safiullin, \& Bagautdinova, 2012). The consumption of other minerals, especially non-ferrous and alloy metals, increased by 3-5 times for the same period, and the raw materials for fertilizer production by 3.5 times. It is expected that in the next 50 years, the world consumption of oil will increase by approximately a factor of 2 , natural gas - 3, iron ore - 1.5, primary aluminum - 2, copper - 1.5, Ni - 2.7, zinc - 1.3, and other minerals - 2.2-3.5 times (Melnik \& Mustafina, 2013).

Over the past half century as a result of economic activity about 2 million hectares of land or $23 \%$ of all arable and pasture land, forest, and wetlands - were under Verger degradation. The forests of the planet are also rapidly reducing, with $20 \%$ of the rainforest destroyed, which was accompanied by the disappearance of many species. One of the critical factors that determine the level of air pollution and the general level of environmental threats is growing production and consumption. Developed countries are making the greatest contribution here. If the average world consumption of energy per capita today was $2701 \mathrm{kWh}$, the OECD countries would contribute$8795 \mathrm{kWh}$, while in developing countries - only $1221 \mathrm{kWh}$ would be used (Safiullin, Elshin, Shakirova, Ermolaeva, \& Prygunova, 2013).

Russia remains in environmental-economic imbalance, despite the decline in the population of the country and reduction in the volume of social production in its 90 years. The fact is that domestic industry is concentrated mainly in areas where the environment does not meet environmental requirements and is dangerous to human health. Apparently, in these areas production will continue to be concentrated, and the labor force will increase. Therefore, reducing the economic burden on the environment is important for us. Environmental troubles in our country is evidenced by many facts. In the ranking of environmentally friendly countries, Russia in 2012 took only 106th place, with 50 to $70 \%$ of its residents living in ecologically unfavorable conditions, breathing polluted air, and drinking low-quality drinking water, only $1 \%$ of which corresponds to world standards (Wyrwich, 2012). The country has accumulated nearly one billion tons of waste in hazard class 1 and 2, including radioactive waste, and about 10 billion tons of $3^{\text {rd }}$ to 4 th grades. The costs of remediation in terms of financing is comparable to the cost of modernizing the army until 2020 - 20 trillion rubles (Gauselmann \& Marek, 2012).

Russian oil companies officially declare production losses (leakage) of oil production, transport, and processing of $1 \%$ of their total. Given that the annual oil production in the country exceeds 500 million tons, they lost 5 million tons annually, and the volume of combusted gas was comparable with the volume of natural gas exported from Russia to Europe. The metallurgical, chemical, energy, pulp and paper industries, etc., also have an extremely negative impact on the environment. Another acute problem is the high level of anthropogenic emissions of greenhouse gases in the environment. According to the national inventory report, anthropogenic emissions of total greenhouse gas emissions in Russia amounted to 66\% of the 1990 level (Bobyleva, 2010). This decrease is due to a deep decline in production in the country. However, the tendency to reduce pollution of the environment increased in the 2000s after the resumption of economic growth. Air pollution from stationary sources and vehicles increased, and the volume of industrial waste after 2005 increased by 2 times. First place in the release of greenhouse gases belongs to carbon dioxide (CO2) with $72 \%$ of total emissions, the source of which is mainly the energy sector - the burning of fossil fuels. In second place was methane (CH4) with $21.6 \%$, which is the main source of which was oil, gas, and coal, as well as livestock. According to expert estimates, the share of Russia, which produces about 3\% of world GDP, accounts for about $8 \%$ of the total greenhouse gas emissions in the world. This is fourth place after China, the U.S., and India. In per capita terms, our country ranks second in the world after the United States. Now the cost of natural resources and pollution per unit of GDP in Russia is 2-4 times higher than in developed countries (Bagautdinova, Gafurov, \& Novenkova, 2013). 
A serious problem of the Russian economy, viewed through the prism of sustainable development, is its ever-increasing focus on exports of raw materials and extractive industries, which causes great damage to the environment. The supply of commodities abroad today accounts for over $90 \%$ of all Russian exports. An environmentally dangerous factor has long been a depreciation of fixed assets, which amounted to $48.6 \%$, in 2012 for the whole country against $39.3 \%$ in 2000 and almost doubling from 1970. This leaders in this are: fisheries and fish farming $64.9 \%$, transport and communications $58.6 \%$, health and social services $55.3 \%$, education $54.9 \%$, mining $53.7 \%$, manufacturing and distribution of electricity and gas, and water $51.2 \%$ (Gilmartin, Learmouth, Swales, McGregor, \& Turner, 2013).

Simultaneously, there was a 2.5 -fold decrease in the rate of renewal of fixed assets and their disposal was reduced from $1.8 \%$ to $0.7 \%$. The average age, in contrast, increased from 8.4 to 26.8 years (Melnik \& Mustafina, 2013). All this may not cover the time of not only moral but also physical deterioration, and does not provide technological reliability and safety.

One of the reasons for the negative phenomena in the ecological-economic sphere is the imperfection of macroeconomic indicators used. This issue is becoming increasingly important. Many reputable researchers suggest (Gauselmann \& Marek, 2012) that traditional macroeconomic indicators such as GDP and GNP) have a number of drawbacks and limitations, and may not be a reliable indicator of economic development. Therefore, the development of new indicators that can reflect the richness of the content of sustainable development is necessary. It should be noted that due to methodological and statistical difficulties of calculation, there is no single universally accepted indicator. This results in the dilemma of choosing the most appropriate indicator for national economies. International organizations have developed a range of versatile features, with which they must comply: easily interpreted; reflect temporal trends; set thresholds against which to be measured; equally respond to scientific and technical approaches; act as numerical values, a reasonable cost of data collection; recorded in documents; updated on a regular basis; and an integrated display of a wide range of particular indicators. The indicator of adjusted net (true) savings, developed by the World Bank, can be used as such (Nurtdinov \& Nurtdinov, 2014). The main content of this indicator is based on the calculation of economic assets which are generated by the country, adjusted for depletion of mineral, environmental, energy, and damage to the natural environment, and an amount of assets or net savings which can be used for future generations.

Correction of gross domestic savings occurs in two stages. At the first stage the value of net domestic savings (NDS) is calculated as the difference between gross domestic savings (GDS) and the value of the depreciation of productive assets (CFC). In the second stage, net domestic savings is increased by the amount of expenditure on education (EDE), and reduced by the amount of natural resource depletion (DPNR) and damage from environmental pollution (DME):

$$
\mathrm{GS}=(\mathrm{GDS}-\mathrm{CFC})+\mathrm{EDE}-\mathrm{DPNR}-\mathrm{DMGE} \text {. }
$$

The above formula yields net savings used to calculate the data by country, and all data used in it are taken as a percentage of GDP. We propose to optimize this formula and calculate the index value (absolute) terms (Nurtdinov \& Nurtdinov, 2014):

$$
\mathrm{GS}=\mathrm{GDP}-(\mathrm{LSF}+\mathrm{HP})-\mathrm{ITS}-\mathrm{CPD}-\mathrm{VA}+\mathrm{RO}+\mathrm{RH}+\mathrm{RSPFK},
$$

where GS - genuine savings; GDP - Gross Domestic Product; ACH - actual consumption of households; PG public consumption; DFA- the depletion of fixed assets; CNR - consumption of natural resources; EHSAemissions of harmful substances into the atmosphere; SE - spending on education; EH - expenditure on health; SPEPC- social policy expenditures and physical culture. To solve this problem, as with the initial data, we use the materials of the Federal State Statistics Service. The results of our calculations of the true savings of the Russian Federation is presented in Table 1.

As can be seen from Table 1, there was a positive GDP growth rate in the Russian Federation in 2005 - 2011 simultaneously accompanied by negative genuine saving rates. This testifies to the poor quality of economic growth, which results in depletion of natural capital and environmental degradation. Corresponding correction leads to a significant reduction in traditional economic development indicators (GDP and GNP), pushing them into negative territory. It should be noted that our calculations are generally in line with the results of studies conducted by the World Bank (Nurtdinov \& Nurtdinov, 2014).

They show that all the countries in the analysis showed positive values, and only Russia was in the negative zone, which certainly significantly devalues the official estimates of the positive growth of the country in the 2000s. Having a significant impact on the country's real savings, as international experience shows, are the costs of providing education, health, social policy, and physical culture (Robine, 1991). However, according to our 
calculations, this impact was insignificant, which means, on the one hand, the high value of the factors of natural resource depletion, depreciation of fixed assets, emissions of harmful substances into the atmosphere in the structure of the test indicator, and on the other, - a low level of social financing. The results of our comparisons are reflected in Figure 2.

Table 1. Results of calculation of genuine savings of the Russian Federation

\begin{tabular}{cccccccc}
\hline & $\mathbf{2 0 0 5}$ & $\mathbf{2 0 0 6}$ & $\mathbf{2 0 0 7}$ & $\mathbf{2 0 0 8}$ & $\mathbf{2 0 0 9}$ & $\mathbf{2 0 1 0}$ & $\mathbf{2 0 1 1}$ \\
\hline GDP & 21509,76 & 26917,20 & 33247,51 & 41276,84 & 38807,22 & 45172,74 & 54585,23 \\
ACH\& PG & 12391,10 & 15160,80 & 18742,40 & 23446,00 & 29351,00 & 32070,00 & 37254,00 \\
DFA & 4209,80 & 4209,80 & 5276,20 & 6332,60 & 7618,00 & 8196,00 & 9123,30 \\
Oil & 5847,95 & 5870,07 & 8811,55 & 4132,01 & 9158,37 & 10847,76 & 12081,10 \\
Gas & 1513,12 & 1907,16 & 1999,98 & 2799,77 & 2476 & 2907,83 & 3602,27 \\
Coal & 334,58 & 471,2 & 474,77 & 558,64 & 487,62 & 670,41 & 746,38 \\
EHSA & 17,33 & 16,8 & 15,84 & 15 & 18,2 & 17,4 & 16,93 \\
EH & 85,6 & 141,9 & 192,9 & 330,8 & 431,4 & 426,9 & 466,4 \\
SE & 163 & 227,1 & 319,3 & 384,4 & 448,10 & 456,8 & 531,2 \\
SPEPC & 248,6 & 369 & 512,2 & 715,2 & 879,5 & 883,7 & 997,6 \\
GS (billions of rubles) & $\mathbf{- 2 ~ 3 0 6 , 9 2}$ & $\mathbf{1 9 , 3 7}$ & $\mathbf{- 1 ~ 0 4 8 , 8 3}$ & $\mathbf{5 4 2 3 , 2 2}$ & $\mathbf{- 8 ~ 5 4 3 , 4 4}$ & $\mathbf{- 7} \mathbf{7 6 9 , 2 6}$ & $\mathbf{- 6} \mathbf{2 4 3 , 5 5}$ \\
\hline
\end{tabular}

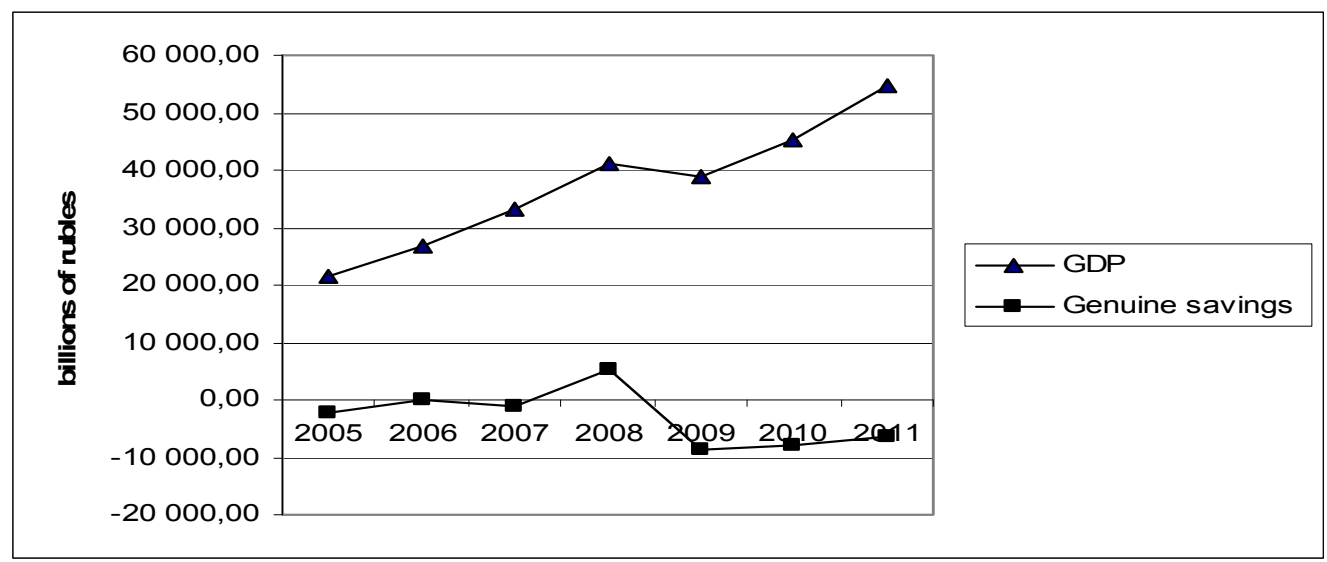

Figure 1. Graphical display of genuine savings calculations of the Russian Federation

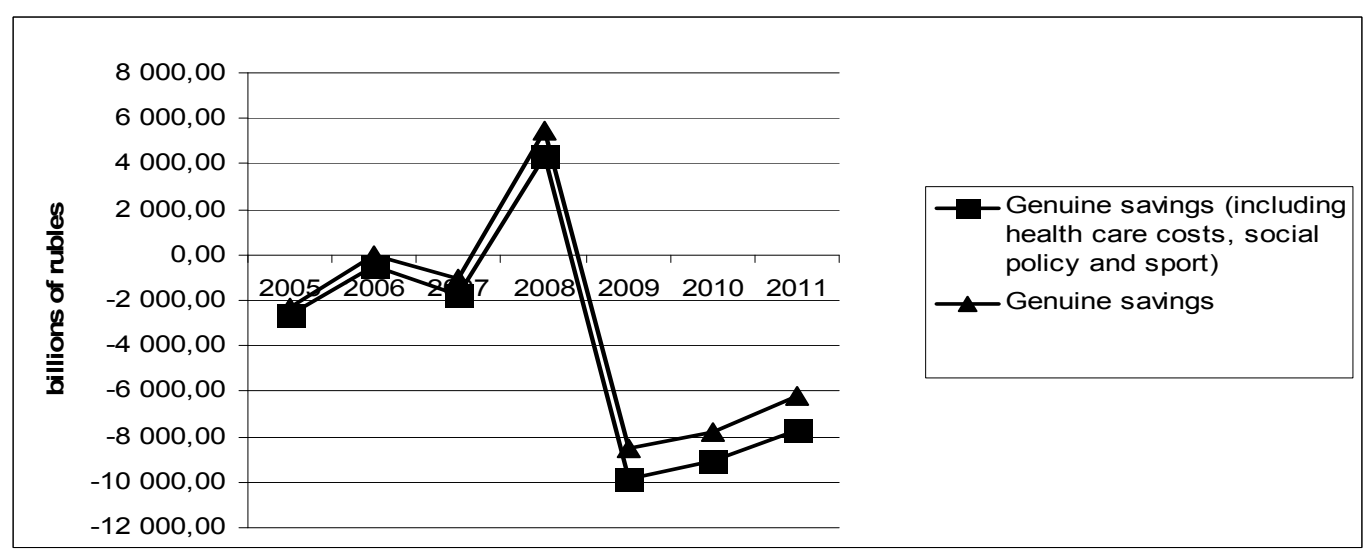

Figure 2. Impact of health care costs, social policy and physical culture to change the dynamics of genuine savings Russia 
Certainly, the index of adjusted net savings is not an ideal indicator and has a number of drawbacks. However, its use provides a constructive result, since it allows us to determine the aggregate assessment of economic development, as well as measure the depletion of natural and human capital. The analysis leads to the conclusion that Russia faces serious environmental problems and limitations caused by both internal and external reasons. The results of operations of the State in the field of sustainable development cannot match the scale of the country or its potential and provide ecological and economic equilibrium. No tangible progress in attracting public and private companies to meet the challenges of sustainable development on the basis of innovation has been made. The modern model of economic growth creates a huge burden on the environment.

\section{Conclusions}

Russia cannot afford to slow economic growth, but at the same time it is unable to continue to ignore aggravated ecological and economic contradictions, and their negative impact on the nature of economic development. There is an urgent need to find new technological solutions aimed at energy saving and the use of new eco-efficient fuels. The state and the private sector for environmental protection need reorientation of financial flows. The transition to sustainable development based on environmentally oriented production and consumption patterns, has become the main imperative of modernity, for the survival of the human species and natural conservation.

\section{References}

Bagautdinova, N. G., Gafurov, I. R., \& Novenkova, A. Z. (2013). The transformation of region's economic area governed by the development of industrial region. World Applied Sciences Journal, 25(7), 1113-1117.

Bobyleva, S. (Ed.). (2010). Report on Human Development in the Russian Federation 2009 (p. 163).

Gauselmann, A., \& Marek, P. (2012). Regional determinants of MNE's location choice in post-transition economies. Empirica, 39(4), 487-511.

Gilmartin, M., Learmouth, D., Swales, J. K., McGregor, P., \& Turner, K. (2013). Regional policy spillovers: The national impact of demand-side policy in an interregional model of the UK economy. Environment and Planning, A45(4), 814-834.

Huning, S., Naumann, M., Bens, O., \& Hüttl, R. F. (2011). Transformations of modern infrastructure planning in rural regions: The case of water infrastructures in Brandenburg, Germany. European Planning Studies, 19(8), 1499-1516.

Melnik, A. N., \& Mustafina, O. N. (2013). The Organization of Russian Power Market in Modern Conditions. Middle-East Journal of Scientific Research, 91-94.

Nurtdinov, R. M., \& Nurtdinov, A. R. (2014). Assessment of the Dynamics of Growth Factors in Russia. Mediterranean Journal of Social Sciences, 5(18), 361-366.

Robine, J. M. (1991). Healthy life expectancy: evaluation of global indicator of change in population health. British Medical Journal, 302.6774, 457.

Safiullin, L. N., Ismagilova, G. N., Safiullin, N. Z., \& Bagautdinova, N. G. (2012). The development of welfare theory in conditions of changes in the quality of goods and services. World Applied Sciences Journal, 18, 144-149.

Safiullin, M. R., Elshin, L. A., Shakirova, A. I., Ermolaeva, P. O., \& Prygunova, M. I. (2013). Influence of Territorial Ecological Load Factors on Social and Economic Well-Being of Population: Methodology Development and Econometric Model Construction. World Applied Sciences Journal, 25(7), 1057-1061.

Wyrwich, M. (2012). Regional Entrepreneurial Heritage in a Socialist and a Postsocialist Economy. Economic Geography 88(4), 423-445.

\section{Copyrights}

Copyright for this article is retained by the author(s), with first publication rights granted to the journal.

This is an open-access article distributed under the terms and conditions of the Creative Commons Attribution license (http://creativecommons.org/licenses/by/3.0/). 